\title{
Cultural Practices and Academic Performance of Blaan Pupils in Sinapulan Elementary School
}

\author{
Mark Steve Alentajan Francisco', Dolorcita Ebona Pauya $^{2}$, Cristobal Millenes \\ Ambayon ${ }^{3}$ \\ ${ }^{1}$ Teacher III, Lasak Elementary School, Columbio District II, Sultan Kudarat Division, Mindanao, Philippines \\ ${ }^{2}$ Professor VI, Sultan Kudarat State University, ACCESS, EJC Montilla, Tacurong City, Sultan Kudarat, \\ Mindanao, Philippines \\ ${ }^{3}$ Associate Professor V, Sultan Kudarat State University, College of Teacher Education, ACCESS, EJC \\ Montilla, Tacurong City, Sultan Kudarat, Philippines \\ jophkris_01@yahoo.com,cristobalambayon@sksu.edu.ph
}

\begin{abstract}
This study generally aimed to determine the level of cultural practices and academic performance of the Blaan pupils in Sinapulan Elementary School, Sinapulan, Columbio, Sultan Kudarat. Moreover, it was intended to find out which of these practices are still prevalent. The study employed the descriptive method of research. The researchers utilized a self-formulated survey questionnaire which was validated and approved by a panel of experts. The same underwent tests of validity and reliability. The statistical tools utilized in the study were mean, standard deviation, t-test, ANOVA and correlation. Majority of the respondents were males, whose parents were elementary graduates. The extent of cultural practices as perceived by Blaan pupils was Highly Evident. Their level of academic performance was Satisfactory. There was a significant relationship between the pupils' extent of cultural practices and their academic performance. There were no significant differences in their academic performances as to gender, age, parents' educational attainment and monthly family income.
\end{abstract}

Keywords cultural practices; academic performance; indigenous communities; ethnic identities; Blaan culture

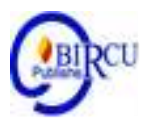

\section{Introduction}

A society's cultural practices can be conceptualized in terms of the incidence or prevalence of behaviors or the actions of groups and organizations. People's ability to change such cultural practices depends on the development of a science of cultural practices, Biglan (1995). Indigenous communities, peoples and nations are those which having a historical continuity with pre-invasion and pre-colonial societies that developed on their territories, consider themselves distinct from other sectors of societies now prevailing in those territories, or parts of them. They form at present non-dominant sectors of society and are determined to preserve, develop, and transmit to future generations their ancestral territories, and their ethnic identity, as the basis of their continued existence as peoples, in accordance with their own cultural patterns, social institutions and legal systems." Martinez-Cobo as cited by the Secretariat of the United Nations Permanent Forum on Indigenous Issues (2011). In the Philippines, Blaan culture is one of the most colorful and exotic tribes. The Blaans who are one of the minority ethnic groups, currently comprise the third largest cultural minority living within the island. The tribe's culture is consist of religious beliefs and practices ranging between customs and traditions directly associated with the established churches in 
the areas to highly traditional animistic belief which encompasses both natural and supernatural elements from the environment in which they live. In Sinapulan Elementary School, majority of the pupils are Blaan. Some of them are dropping out due to early marriage. Their academic performance is an interesting issue to tackle since most of the interviews conducted by the researchers showed that their parents were not able to finish school hence, some cannot read, write or count. Also, it was noted that some of them commit absences as they are obliged by their parents to help in the farm to earn a living. Some tend to quit school after long days of absence from school. The level of cultural practices of this tribe and its relationship to their academic performance prompted the researchers to conduct this study as these variables are hypothesized to be correlated. Also, the differences in the academic performance of Blaan pupils as to their demographic profile will be of great value to the school community as this will serve as an eye opener and baseline data for designing academic interventions and program.

\subsection{Objective and Research Questions}

This study generally aimed to determine the level of cultural practices and academic performance of the Blaans in Sinapulan Elementary School, Sinapulan, Columbio, Sultan Kudarat. Moreover, it was intended to find out which of these practices are still prevalent. Specifically, it sought to answer the following questions:

1. What is the demographic profile of Blaan pupils in terms of:

a. Gender;

b. Age;

c. Educational Attainment of Parents; and

d. Family's Monthly Income?

2. To what extent are the cultural practices of Blaan as perceived by the pupils in terms of:

a. Marital;

b. Religious;

c. Political; and

d. Socio-Economic?

3. What is the level of academic performance of Blaan pupils?

4. Is there a significant relationship between the Blaan pupils' level of cultural practices and academic performance?

5. Are there significant differences among the Blaan pupils' academic performance across demographic profile?

\section{Research Methods}

This study was conducted at Sinapulan Elementary School, located in Barangay Sinapulan, Municipality of Columbio, Province of Sultan Kudarat, Mindanao, Philippines for the School Year $2017-2018$.

\subsection{Research Designs}

This study employed the descriptive method of research. It descriptively explored the evident cultural practices of Blaan pupils and their academic performance. It also determined the significant relationship between their level of cultural practices and academic performance. Finally, it also determined the significant differences among the Blaan pupils' level of cultural practices across profile. 


\subsection{Respondents of the Study}

The respondents of the study were the one hundred thirty-eight (138) intermediate pupils of Sinapulan Elementary School, Columbio, Sultan Kudarat.

\subsection{Research Instruments}

The study formulated a two-part questionnaire on the assessment of Blaan pupils' cultural practices and academic performance. The first part contained the demographic profile. The second part contained the questions regarding the pupils' level of cultural practices such as marital, religious, political and socio-economic practices. The average grades for the First Quarter from (June - August) and Second Quarter from (September November) of the pupils were taken as basis for their academic performance. On the level of cultural practices of Blaan pupils, the following 5-Point Likert's Scale was used.

\subsection{Data Gathering Procedures}

The researchers formally asked permission to the Schools Division Superintendent of the Division of Sultan Kudarat down to the school administrator to conduct the research. The researchers asked also the permission of the Regional Office on National Commission on Indigenous Peoples (NCIP). Formal communication was sent seeking permission to utilize Blaan pupils as respondents of the study and the researchers also asked permission to the Office of the Principal for the documents needed especially the report cards to determine their academic performance. There were four (4) personnel from the National Commission on Indigenous People (NCIP) from Provincial Office who assisted in gathering the data in coordination with the community leaders of Barangay Sinapulan, Columbio, Sultan Kudarat.

\subsection{Statistical Treatment}

To analyze the data gathered from the survey questionnaires, standard deviation and mean were utilized to describe the Blaan pupils' level of cultural practices and their academic performance. The Pearson product moment of correlation coefficient was utilized in looking into the significant relationship between the Blaan pupils' level of cultural practices and their academic performance. ANOVA and t-test were also used in looking into the significant difference of the Blaan pupils' academic performance across profile. All statistical tests were set at 0.05 level of significance.

\section{Results and Discussion}

\subsection{Results}

The data is presented sequentially according to the order of the research problem. The discussions covered the following: The demographic profile of the respondents in terms of gender, age, educational attainment of parents, and monthly income of the family; The Blaan pupils' level of cultural practices in terms of marital, religious, political, and socio-economic; The level of academic performance of Blaan pupils in the first and second quarters; The significant relationship between the Blaan pupils' level of cultural practices and academic performance; and the significant differences among the Blaan pupils' academic performance across profile. 


\section{a. The Demographic Profile of Blaan Pupils}

The first research problem aimed to describe the demographic profile of Blaan pupils in terms of their gender, age, parents' educational attainment, and family's monthly income.

The pie chart shows the Blaan pupils profile in terms of their gender.

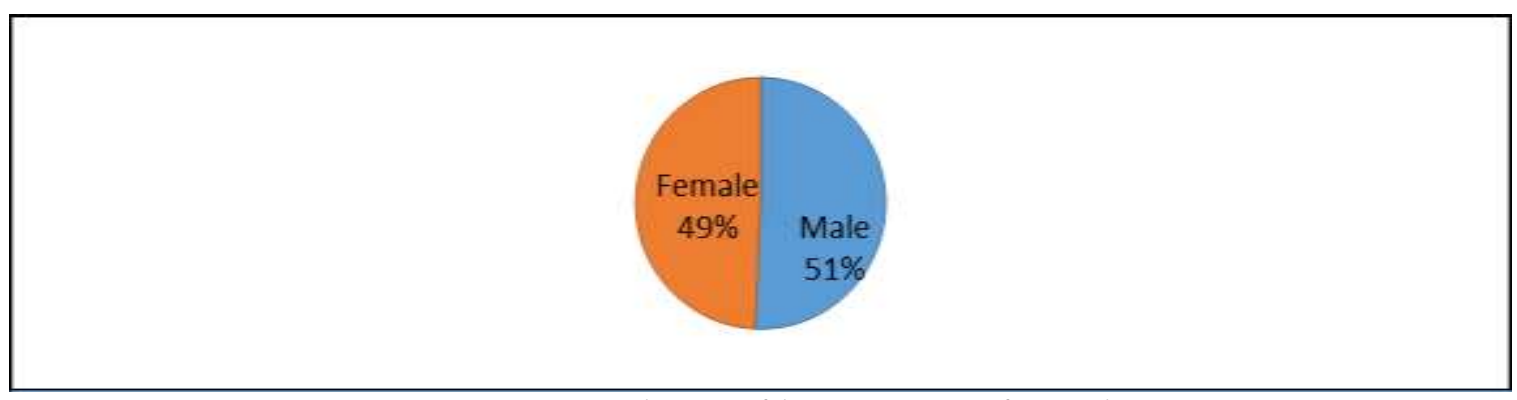

Figure 1. Pupils' Profile in Terms of Gender

As revealed on the pie chart, majority of the Blaan pupils (70 or $51 \%)$ are males while the remaining (68 or 49\%) were females. This result further reveals that the percentage of male and female Blaan pupils are almost the same. This result is applicable only for the current school year based on the list of bona fide Blaan pupils enrolled.

Another variable considered in the research study is the respondents' age, the variable often used to compare academic performances, beliefs, perceptions and levels. The next bar graph shows the profile of the respondents when classified according to age.

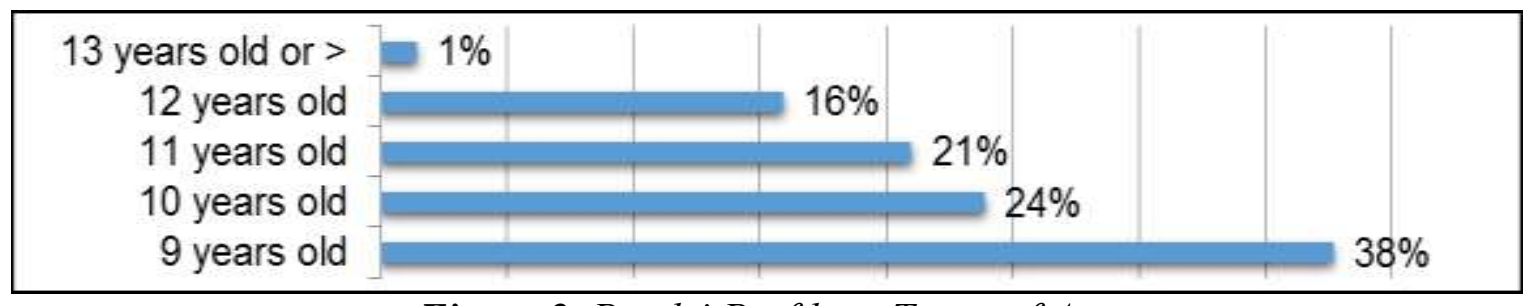

Figure 2. Pupils' Profile in Terms of Age

As shown on the bar graph of the 138 Blaan respondents, $38 \%$ are 9 years old; $24 \%$ are 10 years old; $21 \%$ are 11 years old; $16 \%$ are 12 years old; and $1 \%$ is 13 years old. The results further revealed that majority of the respondents are 9 years old and the least is 13 years old. This is in agreement to the distribution of respondents by grade level where majority of them belong to Grade IV classes whose ages range from $9-12$ years old.

This study also aimed to describe the respondents' profile in terms of their parents' highest educational attainment. The succeeding graph shows the results for this variable.

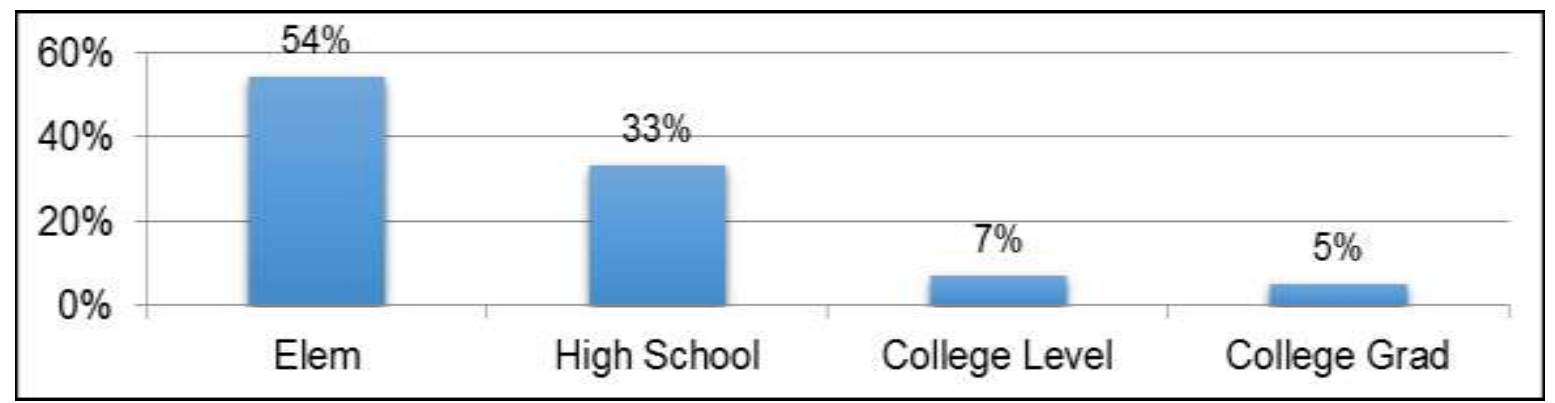

Figure 3. Pupils' Profile in Terms of Parents' Educational Attainment 
As shown in the graph, most of the pupils' parents had reached the elementary level only as evidenced by $54 \%$ while only $5 \%$ are college graduates. Also, $33 \%$ of them had finished the high school level and the remaining 7\% are college level. It is very interesting to note these results because these data also correlated with the pupils' academic performance.

The last variable under the respondents' profile is the family monthly income. The next graph shows the results for this variable.

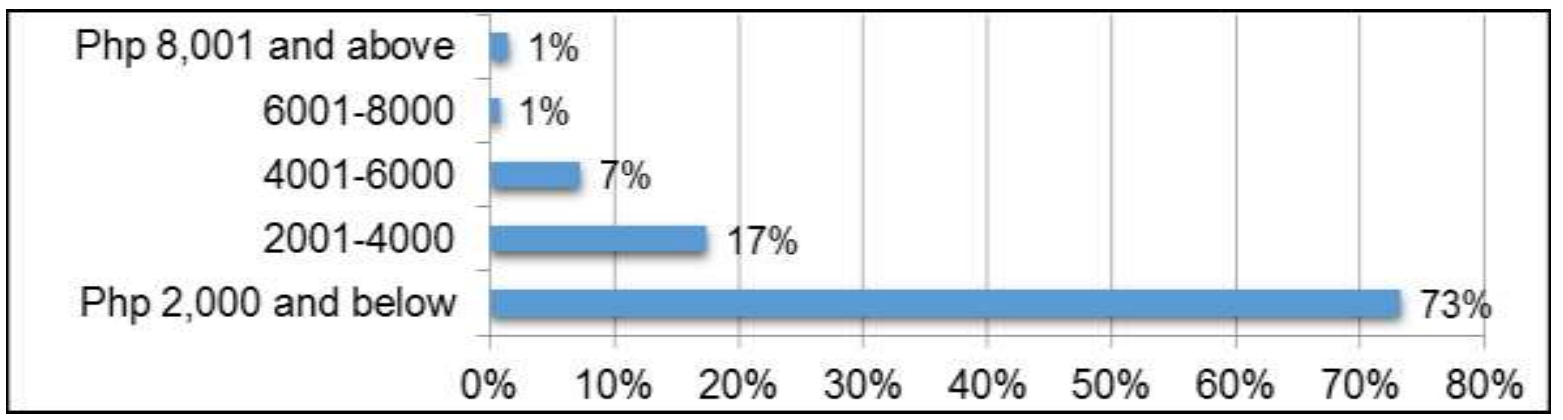

Figure 4. Pupils' Profile in Terms of Family's Monthly Income

As revealed in the graph, majority $(73 \%)$ of the Blaan families have monthly income of Php 2,000 and below, $17 \%$ claimed to have an monthly income within the range of Php2001 - Php 4,000, 7\% within the range Php 4,001 -Php 6,000, 1\% within the range of Php 6, 001 - Php 8,000 and the remaining 1\% declared to have monthly income of Php 8001 and above. This imply that majority of them cannot have permanent jobs unlike those who are educationally qualified.

\section{b. Cultural Practices of Blaan Pupils}

Table 1. Summary of Pupils' Extent of Cultural Practices

\begin{tabular}{lccc}
\hline \hline Practices & Mean & $\begin{array}{c}\text { Verbal } \\
\text { Description }\end{array}$ & Interpretation \\
\hline Marital & 3.04 & Sometimes & Moderate Extent \\
Religious & 3.47 & Often & High Extent \\
Political & 3.37 & Often & High Extent \\
Socio-Economic & 3.54 & Often & High Extent \\
\hline Grand Mean & $\mathbf{3 . 3 6}$ & Often & High Extent \\
\hline \hline
\end{tabular}

Table 1 summarizes the pupils' extent of cultural practices. It is noted that the computed Grand Mean rating of 3.36, verbally described as "Often" and interpreted as "High Extent" which implies that the cultural practices of Blaan pupils are to a "High Extent" in the local community and that these are practiced oftentimes. The highest computed mean is posted at Socio-Economic Practices with the computed mean of 3.54, verbally described as "Often" and interpreted as "High Extent". Along with this are the Religious and Political Practices with 3.47 and 3.37 respectively. The lowest of the identified cultural practices are posted on Marital with the computed mean rating of 3.04 
verbally described as "Sometimes" and interpreted as Moderate Extent. Biglan (1995) stated that a society's cultural practices can be conceptualized in terms of the incidence or prevalence of behaviors or the actions of groups and organizations.

\section{c. Academic Performance of Blaan Pupils}

The third research problem aims at determining the level of academic performance of the Blaan pupils in the first and second quarters of the current school year as reflected in Table 2.

Table 2. Summary of Academic Performance of Blaan Pupils

\begin{tabular}{lcl}
\hline Quarters & Mean & Grade Verbal Rating \\
\hline First Quarter & 80.71 & Satisfactory Performance \\
Second Quarter & 80.76 & Satisfactory Performance \\
\hline Grand Mean & $\mathbf{8 0 . 7 4}$ & Satisfactory Performance \\
\hline
\end{tabular}

The Table reveals that the Grand Mean of their academic performances is posted at 80.74 with the description "Satisfactory Performance". This implies that the academic performance of Blaan pupils is of a satisfactory level. The mean for the first quarter is 80.71 verbally described as "Satisfactory Performance". On the second quarter, the mean of the pupils increased by 0.05 totaling to 80.76 still verbally described as "Satisfactory Performance". It is worthy to note that in educational institutions, success is measured by academic performance, or how well a student meets standards set out by local government and the institution itself. The findings conforms with the study of Ingalls, et.al. (2006) that culture plays an important role in influencing a child's learning process and the skills that are learned.

\section{d. Relationship between Blaan Pupils' Cultural Practices and Academic Performance}

The fourth research problem aimed to test the significant relationship between the Blaan pupils' level of cultural practices and academic performance. Table 3 shows the results for this test.

Table 3. Relationship between Cultural Practices and Academic Performance

\begin{tabular}{lllcc}
\hline \hline Variables & Mean & Variance & $\begin{array}{c}\text { Pearson } \\
\mathbf{r}\end{array}$ & $\mathbf{r}_{\text {crit(.05) }}$ \\
\hline $\begin{array}{l}\text { Cultural } \\
\text { Practices }\end{array}$ & 3.36 & 0.18 & -0.17 & 0.15 \\
$\begin{array}{l}\text { Academic } \\
\text { Performance }\end{array}$ & 80.74 & 10.73 & & \\
\hline \hline
\end{tabular}

Note: $\mathrm{df}=136$ 
Table 3, reveals the results of the t-test between the extent of cultural practices and the level of academic performance of Blaan pupils. Since the computed $r$ value of $[<0.17\rangle]$ was greater than the $r$ critical value of 0.15 at 0.05 level of significance, then the $\mathrm{Ho}$ is rejected. Hence, the relationship is significant between the pupils' extent level of cultural practices and academic performance. This is in consonance with Hill (2012) who concluded that culturally responsive teachers are also aware of the critical role that race and culture play in the way that students learn.

\section{e. Significant Differences in Academic Performance of Blaan Pupils across Demographic Profille}

The final research objective aimed to determine the significant differences among the Blaan pupils' academic performance across profile. The succeeding Tables shows these results.

Table 4. Analysis of Academic Performance of Blaan Pupils across their Gender

\begin{tabular}{lllll}
\hline \hline Gender & Mean & SD & t & $\mathbf{t}_{\text {2-tailed crit.05) }}$ \\
\hline Female & 80.382 .50 & 1.295 & 1.979 \\
Male & 81.103 .73 & & \\
\hline
\end{tabular}

\section{Overall Mean 80.74}

Table 4, revealed the results of the t-test between the Blaan pupils' academic performance across their gender. As shown, the computed t-value of 1.295 is lower than the tabular t-value of 1.979 implying the acceptance of the null hypothesis at 0.05 level of significance. There is no significant difference between the academic performances of Blaan pupils when classified according to gender. This further implied that there is no significant difference.

\subsection{Discussion}

Blaan is a coined word "bla" and "an". Bla means counterpart or pair and suffix an expresses ownership or possession. The Blaans are further classified based on the traditional territories they dwell/occupy. There are Blaans who live in the plains (Blaan Datal), those that live in the interior part of the mountains (Blaan Lagad), those that preferred to stay near the ocean (Blaan Mahin) and those that live in communities with large coconut plantation (Blaan Lam Alfo). There are also younger generation Blaans (tubad Blaan) that are living outside the Philippines as immigrants, Overseas Filipino Workers, and missionaries whom we call as Blaan Internationals, Kafye Blaan Empowerment, Inc.( 2015). In addition, the following provides the basic criteria when identifying indigenous peoples they live within or maintain close attachments to geographically distinct, ancestral territories; they tend to maintain distinct social, economic and political institutions within, their territories; they aspire to remain distinct culturally, geographically and institutionally, rather than assimilate fully into national society; and they self-identify as indigenous or tribal, Secretariat of the United Nations Permanent Forum on Indigenous Issues (2011). Moreover, Gilbert's (2016) book addresses 
the right of indigenous peoples to live, own and use their traditional territories, and analyzes how international law addresses this.

\section{a. Cultural Practices}

Biglan (1995) stated that "A society's cultural practices can be conceptualized in terms of the incidence or prevalence of behaviors or the actions of groups and organizations. The solution of any societal problem can be conceived in terms of the modification of those practices. People's ability to change such cultural practices depends on the development of a science of cultural practices.

Culture grows out of the patterned ways that people in a group respond to the fundamental problems of social interaction, Trompenaars (1996) as cited by Brett and Gelfand (2005). Culture has been, and continues to be, defined in many ways. Similarly, it is a system of symbols, meanings, and norms passed from one generation to the next, which differentiates groups of people united by certain characteristics such as origin, race, ethnicity, gender, religion, socioeconomic class, or political views, Savignon \& Sysoyev (2002). According to Donkor (2013), culture becomes an integral part of human existence that it is the human environment, and most, cultural change can be attributed to human adaptation to historical events.

In the Philippines, the practices and beliefs in the different inhabitants in Mindanao result in big differences of practices and beliefs. Discrimination is common and this happens everywhere. Despite this, Lumads, Catholic Christians, and Muslims are free to express their beliefs and practices. Lumads have not succumbed to the modern ways of living. Up to this day, they prefer to live in the mountainsides of Mindanao, living the traditional life. Their beliefs can be seen through the ornaments of every woman and the woven dresses they wear. They believe in spirits and gods. For them, the mountain is sacred. Death and illness or bad faith is believed to be the god's way of showing anger. Offering of live animals like pigs and chicken is common during tribal ceremonies for a good harvest, health and protection, and thanksgiving.

Furthermore, McQuillan (1998) as cited by George and Aronson (2003) stated that the belief systems that emanate from our culture shape the way we think, live, act, and interact with each other and with those outside our culture. Our expectations and cultural belief systems reflect our values and perspectives and at the same time can close our minds to accepting other ways of thinking and doing. Surprisingly, Coomaraswamy (2002) reported that the Special Rapporteur gave special attention in the report to dominant ideologies and structures within societies that perpetuate cultural practices that are violent towards women, including the regulation of female sexuality and masculinity and violence. Many of the cultural practices discussed in the report are based on a society's belief that the freedom of a woman, especially her sexual identity, should be curtailed and regulated.

\section{b. Marital Practices}

In many indigenous communities, marriage is considered one of the most important rites of passage of its members, both male and female. Its importance can be seen in the extent of the lavish celebrations that take place during the union of man and a woman in the sacred rites of marriage. From a functionalist perspective, marriage is a basic human institution created to perpetuate the human species. In this perspective, marriage is a requirement, and both men and women are duty bound to go through this rite of passage as a member of a particular community and culture, Cagoco-Guiam (2012).

The right to marriage, or to found a family is protected as a basic human right, guaranteed by no less than the Universal Declaration of Human Rights (UHDR), first 
promulgated after the Second World War, specifically in 1948. Sections 1 and 2 of Article 16, of the UHDR states thus:

....Men and women of full age...have the right to marry and found a family. They are entitled to equal rights as to marriage, during marriage, and at its dissolution...Marriage shall be entered into only with the free and full consent of the intending parties.

However, when the "intending parties" in the marriage are both children, or when one of the parties is still defined as a child (under 18 years old), then such "free and full consent" is not possible. At that age the function of the reproductive organs is in optimal condition, while at the age of less than 20 years the condition is still in growth, so that food input is widely used for maternal growth which can cause fetal growth disorders (Demmouche A, Khelil S, 2011) as cited by Safrina, et.al (2021). Decision-making on one of the most important events of one's life such as marriage is critical and needs mature thinking, something that may be lacking, or absent, when one of the parties contracting the marriage is still a child, United Nations (2015). Other international conventions on the rights of children and women, like the famous1979 Convention on the Elimination of all Forms of Discrimination against Women (CEDAW) reinforces the right of parties entering marriage to "...freely choose a spouse and to enter into marriage only with their free and full consent..." An additional article in the CEDAW (Article 16.2) explicitly states that "the betrothal and the marriage of a child shall have no legal effect, and all the necessary action, including legislation, shall be taken to specify a minimum age for marriage", Lewis (2006). Among indigenous peoples in South-Central Mindanao, the phenomenon of early marriage has been reported to be common. The socio-political impact of early marriage, seen from the perspective of human rights, is also among the least tackled in the few studies on early marriage among indigenous peoples in Mindanao, Cagoco-Guiam (2012). Pre-arranged marriage is a marriage pre-arranged by both parents of the bride and the groom. They are proposed and contracted through the negotiation and decision between their parents or someone of the couple's family rather by each other. Both parents decide the dowry which includes: the necklace, gong, carabao, horse, brass container with betel nut mixed with line and a certain amount of money as agreed added Tinio (1993). Furthermore, Matas (2015) in his article described the lives' experiences among Blaan secondary students who are involved in pre-arranged marriage. Phenomenological approach was employed with 14 students. In-depth interview and focus group discussion were conducted which revealed that pre-arranged marriage in Blaan tribes is prevalent and contracted by both bride's and the groom's parents. There were eight major themes emerged as experienced by pre-arranged marriage students such as agony and torment, confined and held captive, contempt, absence of courtship, violence, suffering and deprivation, harmonization, and freedom regained. The participants of the study had different approaches in coping with the experience, through support system, diversion of focus, toleration and acceptance and faith in the Divine. Based on the results of the study, it came out that pre-arranged marriage of Blaan secondary female students were found to have particular aspirations pertaining to their marriage, education and career, but lacked confidence in their abilities to create the desired future, which made me conclude that marrying early through pre-arranged marriage is detrimental to their educational attainment.

\section{c. Religious Practices}

A strong belief to a supreme being is a positive attitude and practices among the Blaan for they don't relay most on luck when it comes to their performance. Having a leader or Fulong could influence a child's performance by serving as a role model to the 
children. Early marriage somehow has a great impact on the learners' performance and children tends not to finish schooling and studies. That's why it is rare or uncommon among the Blaan to pursue their dreams. Parents' efforts and struggle to earn for a living is not enough to increase the pupils' performance in school. It should be added with motivation, commitment and partnership to the school and the stakeholders to encourage learning and the importance of education among their young's.

(https://www.k12.wa.us./Equity/Religion/Religious.pdf,retrievedJuly 13, 2017).

\section{d. Political Practices}

The Blaan community (Banwu) was ruled by Datu or village chieftain known as Fulong meaning the wise man. A Fulong is the oldest and wise man in the village with a considerable amount of wealth in the form of gold, slaves, and the cultural materials. The ruler-ship is non-formal, recognizing the Fulong in the course of time by the will of the people without a formal selection process or appointment. To the Blaan, wisdom is a gift from Dawata or God, the person such endowed becomes the sole heir to ruler-ship. In some instance, a person becomes a Fulong by virtue of physical superiority in being a champion warrior. A Blaan Fulong does not require his people to pay tribute to him. However, by virtue of love, and respect, the people give him gifts or offering. A wealthy Fulong could have as many wives as he could support, either by captive or by means of purchase. The Fulong is looked upon as the leader, protector, mediator, and solution giver, A Fulong, according to Blaan custom and tradition, must display exceptional leadership qualities. He must be fair, decisive and firm particularly in selections involving dispute resolution. The Fulong is knowledgeable in distinguishing between good and evil. The term implies that he is skillful in resolving conflict and wise in his decisions. The Bong Fulong must always be treated with the utmost respect, (https://www.blaan.net/traditionalleadership.Retrieved January 20, 2018.

The Blaan leader is chosen by the community from among their nobles. A man or a woman is qualified to become a Fulong (leader) for as long as the man/woman belongs to a fulong libun (family or former leaders or wise men). Once chosen, the Fulung must be brave, loyal to his people, trustworthy, honest kindhearted, merciful, generous, hospitable and friendly to be considered a good leader. This position is heritable by the firstborn. The Fulung serves as the community's lawmaker, the law enforcer and judge, with the assistance of the community's elders. He resolves or decides conflicts. He determines the proper punishment for someone who has committed an offense. His decisions give rise to the laws of the community and sees to it that the laws are followed. With his many responsibilities come several privileges. He is well respected and obeyed at all times. He is allowed to have many wives. He has servants to attend to his family's needs. Whenever he has a visitor, everyone in the community brings food to his house, Kafye Blaan Empowerment (2015).

The Datu and the Fulong or Bong Fulong are considered to be very wealthy individuals within highland Blaan society. (https:/www.blaan.net/traditional-leadership, 2018). Each Datu is the autonomous chief over an areas as far as his personal influence will reach, having authority to conscript labour for conducting negotiations with other Datus. On his death he is succeeded by the eldest son of his first wife, with the approval of the elders, Ureta-Caresma (2011).

\section{e. Socio-Economic Practices}

Reyes, Mina \& Asis (2017) contributed to the scant body of literature on inequalities among and within ethnic groups in the Philippines by examining both the vertical and 
horizontal measures in terms of opportunities in accessing basic services such as education, electricity, safe water, and sanitation. Their study also provided a glimpse of the patterns of inequality in Mindanao. The results showed that there are significant inequalities in opportunities in accessing basic services within and among ethnic groups in the Philippines. Muslims (particularly indigenous people) were the worst-off ethnic groups while the non-indigenous/non-Muslim groups were the better-off groups. Disparities in terms of literacy rate and access to electricity and sanitation between ethnic groups, however, appeared to be narrowing between 2000 and 2010. Similarly, Espiritu (2017) examined the role of alternative media in the socio-environmental movement for justice for the Lumad, the indigenous peoples of the southern Philippines, and the fight to protect the environment in the Philippines from extractive companies and mono-crop plantations.

The prevailing value emphasis in a society may be the most central feature of culture Hofstede, 1980; Inglehart, 1997; Schwartz, 1999; Weber, 1958; Williams, 1958 as cited by Basañez (2015). The rich complex of meanings, beliefs, practices, symbols, norms, and values prevalent among people in a society are manifestations of the underlying culture. In this view, culture is not located in the minds and actions of individual people. Rather, it is outside the individual. According to Belfi, Goos \& Pinxten (2014) culture is very important in shaping our behavior; culture does matter quite a bit too how we behave and how we think.

\section{f. Academic Performance}

In educational institutions, success is measured by academic performance, or how well a student meets standards set out by local government and the institution itself. As career competition grows ever fiercer in the working world, the importance of students doing well in school has caught the attention of parents, legislators and government education departments alike. Parents care about their child's academic performance because they believe good academic results will provide more career choices and job security.

Galiher (2006) and Darling (2005) as cited by Aramay, et. al. (2014) used GPA to measure a student's performance because the main focus is the student performance for the particular semester. Many researchers have discussed the different factors that affect the student academic performance in their research. There are two types of factors that affect the students'academic performance. These are internal and external classroom factors and these factors strongly affect the students'performance. Research studies show that students' performance depends on many factors such as learning facilities, gender and age differences, etc. that can affect a student's performance Hansen, Joe B.(2000) as cited by Aramay, et.al (2014). The process of change did not occur suddenly, but with an evolutive mechanism, slowly but surely, Multajimah, Rusli, Muzakkir, Marzuki (2021).

In line with the implementation of the Enhanced Basic Education Act of 2013 (Republic Act No. 10533), the Department of Education is adopting the enclosed Policy Guidelines on Classroom Assessment for the $\mathrm{K}$ to 12 Basic Education Program. Classroom assessment informs the learners, as well as their parents and guardians of their progress. The $\mathrm{K}$ to 12 Basic Education program uses a standards and competency-based grading system. These are found in the curriculum guides. All grades will be based on the weighted raw score of the learners' summative assessments. The minimum grade needed to pass a specific learning area is 60, which is transmuted to 75 in the report card. The lowest mark that can appear on the report card is 60 for quarterly grades and final grades. For these guidelines, the Department will use a floor grade considered as the lowest possible grade that will appear in a learner's report card. Learners from grades 1 to 12 are graded on 
written work, performance tasks, and quarterly assessment every quarter. These three are given specific percentage weights that vary according to the nature of the learning area. The general average is computed by dividing the sum of all final grades by the total number of learning areas. Each learning area has equal weight. The summary of learner progress is shown quarterly to parents and guardians through a parent-teacher conference, in which the report card is discussed. The grading scale, with its corresponding descriptors, Remarks are given at the end of the grade level (DepEd Order No. 8 s. 2015), Luistro (2015).

\section{Conclusion}

Majority of the respondents were males. Most of them were 9 years old. Majority of their parents were elementary graduates. Most of their family's monthly income was within the range of Php 2,000 and below. The extent of cultural practices as perceived by Blaan pupils was "High Extent". The level of academic performance of Blaan pupils was Satisfactory Performance. There was significant relationship between the pupils' extent of cultural practices and academic performance. There was no significant difference in the academic performance of pupils across their demographic profile.

\section{Recommendations}

Based on the findings and conclusions, it is recommended that teachers have to study further the Blaan culture and must conduct further researches to identify the contributory factors in order to improve the academic performance of the Blaan pupils.

\section{References}

Aramay, R., Corrales, M. M., Dela Rosa, I., Pepito, T. Z., \& Felizardo, M.A. (2014). Psychological Factors Affecting the Learners Academic Performance of Intermediate Students in Amungan Elementary School, S.Y. 2013-2014. Ramon Magsaysay Technological College. Iba, Zambales.

Basañez, M. E. (2016). A World of Three Culture, Honor, Achievement and Joy. Oxford University Press. Stanford California, U.S.A.

Belfi, B., Goos, M., \& Pinxten, M. (2014). Inequality in Language Achievement Growth? An Investigation into the Impact of Pupils Socio-Ethnic Background and School Socio-Ethnic Composition.

Biglan, A. (1995). Changing cultural practices: A contextualist framework for intervention research. Context Press.

Brett, J. M. \& Gelfand, M. J. (2005). The Handbook of Negotiation and Culture. Stanford University Press. Stanford, California, U.S.A.

Cagoco-Guiam, R. (2003). The Impact of Early Marriage Practices: A study of two Indigenous Communities in South-Central Mindanao (T'boli and Blaan) from a human and child rights perspective. Mindanao State University, General Santos City, Philippines.

Coomaraswamy, R. (2002). Integration of the human rights of women and the gender perspective. Violence against women. Report of the Special Rapporteur on violence against women its causes and consequences submitted in accordance with Commission 
on Human Rights resolution 2001/49. Cultural practices in the family that are violent towards women.

Dorkor, A. (2013). Cultural Practices and Education in Ghana: The Effects of Traditional Culture on Parental Involvement in Education

Espiritu, B. F. (2017). The Lumad Struggle for Social and Environmental Justice: Alternative media in a socio-environmental movement in the Philippines. Journal of Alternative and Community Media, 2, 45-59.

George, P. \& Aronson, R. (2003). How Do Educators' Cultural Belief Systems Affect Underserved Students' Pursuit of Postsecondary Resources for Education and Learning. Honolulu, Hawaii, U.S.A. https://www.blaan.net/traditional-leadership. Retrieved: January 20, 2018. https://www.k12.wa.us./Equity/Religion/Religious.pdf. Retrieved: July 13, 2017.

Kafye Blaan Empowerment (2015). Educated and Empowered Blaans with Strong Cultural Identity. http://www.kafyeblaan.com/blog

Lewis, I. (2006). Early Marriage can be a Violation of Children's Basic Right. Zambia: EENET Publisher Enabling Education Network.

Luistro, A. (2015). Policy Guidelines on Classroom Assessment for the $\mathrm{K}$ to 12 Basic Education Program. DepEd Order No. 8. Department of Education. DepEd Complex, Meralco Avenue, Pasig City, Philippines.

Matas, H. B. (2015). Joy and Sorrow of Pre-Arranged Marriage Students. The live's experiences. International Journal of Advancements in Research \& Technology, Volume 4, Issue 6, June -2015 ISSN 2278-7763 36

Multajimah, M., Ris'an, R., Muzakkir, M., \& Marzuki, D. I. (2021). Traditions and Rituals of the Naqsyabandiyah Khalidiyah Babussalam Order (TNKB Practitioners) In the Malay Community Babussalam-Langkat North Sumatra, Budapest International Research and Critics Institute (BIRCI-Journal). Volume 4, Number 1, http:/www.bircu-journal.com/index.php/birci and https://oi.org/10.33258/birci.v4i1.1595. Retrieved. April 8, 2021.

Oko, O. F. (2014). Impact of Teachers Motivation on Academic Performance of Students. Thesis. University of Nigeria. Aba, Abia State, Nigeria

Reyes, C. M., Mina, C. D., \& Asis, R. D. (2017). Inequality of opportunities among ethnic groups in the Philippines (No. 154). World Institute for Development Economic Research (UNU-WIDER).

Safrina, D., Dewi, O., Nurlisis, Mitra, \& Damaya, I. P. (2021). Analysis of Factors that Correlated with Anemia Incidence in Pregnant Women at Working Area of the Sidomulyo Health Center Outpatient UPTD Pekanbaru City. Britain International of Humanities and Social Sciences (BIoHS) Journal, ISSN: 2685-3868(Online), 26851989 (Print) Vol. 3, No. 1, February 2021.

Savignon, S., \& Sysoyev, P. V. (2002). Socio-cultural Strategies for a Dialogue of Cultures, The Modern Language Journal. New Haven: Yale University Press.

Secretariat of the United Nations Permanent Forum on Indigenous Issues (SPFII) (2011). Partnering with Indigenous Peoples: Experiences and Practices. http:/www.un.org/esa/socdev/unpfii/documents/LibraryDocuments/partneringwithips.pdf

Tinio, E. L. (1993). The Blaan: A Tribal Cultural Community of Davao del Sur. Dissertation. Ateneo de Davao University-University of Mindanao, Davao City, Philippines

United Nations (2015). Universal Declaration of Human Rights (UDHR). http://www.un.org/en/universal-declaration- human-rights 
Ureta- Caresma, S. (2011). Leadership of Blaan, Leadership of Men Bong Fulong, Datu, Female Fulong.

Vognar, D. (2012). How Important is Culture in Shaping our Behavior?https://www.huffingtonpost.com/david-vognar/culture-influence-politics- life Wursten, H. \& Jacobs, C. (2013). The Impact of Culture on Education, Itim International. https://geerthofstede.com/tl_files/images/site/social/C ulture\%20and $\% 20$ education.pdf 